\title{
Polymeric immunoglobulin receptor expression is correlated with poor prognosis in patients with osteosarcoma
}

\author{
XUANWEI WANG, JINGYU DU, PENGCHENG GU, RILONG JIN and XIANGJIN LIN \\ Department of Orthopedics, the First Affiliated Hospital, Zhejianåg University \\ School of Medicine, Hangzhou, Zhejiang 310003, P.R. China \\ Received October 11, 2013; Accepted March 12, 2014
}

DOI: $10.3892 / \mathrm{mmr} .2014 .2110$

\begin{abstract}
The prognosis of patients with osteosarcoma with distant metastasis and local recurrence remains poor. Increased expression of polymeric immunoglobulin receptor (pIgR) in tumor tissue has been detected in various types of cancer. However, the clinical significance of pIgR in osteosarcoma has yet to be elucidated. The present study aimed to investigate the prognostic value of $\mathrm{pIgR}$ in patients with osteosarcoma following surgical resection. pIgR expression was assessed using quantitative polymerase chain reaction analysis in cryopreserved osteosarcoma tissues from 22 patients, as well as using immunohistochemistry in paraffin-embedded osteosarcoma tissues from 136 patients. The association between $\mathrm{pIgR}$ expression, clinicopathological factors and long-term prognosis was retrospectively examined in these 136 patients. The prognostic significance of negative or positive $\mathrm{pIgR}$ expression in osteosarcoma was assessed using Kaplan-Meier survival analysis and log-rank tests. Univariate analysis indicated that patients with positive $\mathrm{pIgR}$ osteosarcoma tissue expression had a significantly worse overall survival (OS) compared with patients with negative pIgR osteosarcoma expression. Multivariate analysis revealed that positive $\mathrm{pIgR}$ expression in osteosarcoma tissues was an independent prognostic factor for OS following surgical resection $(\mathrm{P}<0.001)$. Furthermore, positive pIgR expression was significantly associated with poor prognosis in patients with osteosarcoma. These findings indicate that pIgR may be a novel predictor for poor prognosis in patients with osteosarcoma following surgical resection.
\end{abstract}

Correspondence to: Dr Xiangjin Lin, Department of Orthopedics, the First Affiliated Hospital, Zhejiang University School of Medicine, 79 Qingchun Road, Hangzhou, Zhejiang 310003, P.R. China

E-mail: doclinxj@163.com

Key words: osteosarcoma, polymeric immunoglobulin receptor, prognosis

\section{Introduction}

Osteosarcoma is the most common primary malignant bone tumor with highly malignant and invasive growth characteristics in adolescents and young adults (1). Osteosarcoma is associated with a poor prognosis, which is a result of its resistance to chemotherapy and tendency to metastasize to the lungs (2). Using traditional treatment methods, including chemotherapy, wide tumor resection and amputation, patients with osteosarcoma have a poor prognosis, with a five-year survival rate of $<20 \%$ (3). The prognosis of patients with osteosarcoma has improved markedly, primarily due to the introduction of the extensive application of neoadjuvant chemotherapy and limb salvage surgery $(4,5)$. However, the prognosis of patients with advanced osteosarcoma remains poor and advances in treatment are urgently required (6). Effective prognostic factors are important for clinicians to facilitate the selection of appropriate treatments for patients with osteosarcoma.

The polymeric (p) immunoglobulin $(\mathrm{Ig})$ receptor $(\mathrm{R})$ is a transporter of dimeric $\operatorname{Ig} \mathrm{A}$ and pentameric $\operatorname{IgM}$, which are the first-line antibodies produced in response to infection. $\mathrm{pIgR}$ is widely expressed in epithelial cells and its expression is commonly increased by proinflammatory cytokines in response to viral or bacterial infection, linking innate and adaptive immunity (7-10). Upregulation of pIgR has been identified in colon cancer $(11)$, breast cancer $(12,13)$, endometrial carcinoma $(14,15)$, bladder carcinoma (16) and hepatocellular carcinoma (HCC) $(17,18)$. High levels of the cleaved extracellular domain of $\mathrm{pIgR}$, designated as the secretory component, have also been detected in the sera of patients with lung $(19,20)$ and pancreatic cancer (21), as well as patients exhibiting colon cancer with liver metastases (22). However, the clinical significance of $\mathrm{pIgR}$ in osteosarcoma has yet to be elucidated.

The present study aimed to investigate the association between $\mathrm{pIgR}$ expression and clinicopathological features. In addition, the potential of $\mathrm{pIgR}$ as a novel prognostic marker in patients with osteosarcoma following surgical resection was investigated.

\section{Materials and methods}

Patients and tumor tissue samples. Fresh tumor samples were obtained from 22 patients with osteosarcoma at 
Table I. Sequences of primers and probes used for quantitative polymerase chain reaction analysis.

Primer/probe Sequence

\author{
Polymeric immunoglobulin receptor \\ Forward primer \\ Reverse primer \\ TaqMan probe
}

Glyceraldehyde-3-phosphate dehydrogenase

Forward primer

Reverse primer

TaqMan probe

\author{
5'-CTCTCTGGAGGACCACCGT-3' \\ 5'-CAGCCGTGACATTCCCTG-3' \\ 6FAM-5'-AGATCAAGATTATCGAAGGAGAACCAAACCTC-3'-TAMRA
}

\author{
5'-TCCATGACAACTTTGGTATCGTG-3' \\ 5'-ACAGTCTTCTGGGTGGCAGTG-3' \\ 6FAM-5'-AAGGACTCATGACCACAGTCCATGCCA-3'-TAMRA
}

initial surgery at the Department of Orthopedics, the First Affiliated Hospital, Zhejiang University School of Medicine (Hangzhou, China) between January 2010 and December 2012 for quantitative polymerase chain reaction (qPCR) analysis. Samples were snap-frozen and stored in liquid nitrogen until use. Patients had received no treatment prior to surgery. Paraffin-embedded osteosarcoma tissue samples were obtained from 136 patients undergoing surgical resection at the Department of Orthopedics, the First Affiliated Hospital, Zhejiang University School of Medicine between January 1998 and December 2007. None of the 136 patients had received chemotherapy or radiotherapy prior to resection. Following resection, patients were followed up every three months and the sections were reviewed by two pathologists to verify the histological assessment. Informed consent was obtained from all patients and the study protocol was approved by the Ethics Committee of the First Affiliated Hospital, Zhejiang University School of Medicine. The location of the tumors and distant metastases was determined using computed tomography (CT) and magnetic resonance imaging (MRI). The patients with osteosarcoma were staged according to the Enneking staging system (23). The staging workup involved CT scans of the chest to assess for pulmonary metastases, MRI and X-ray scans for local staging, and bone scans to assess for distant skeletal metastases. Patients exhibiting secondary malignancies, for which they had received prior chemoradiotherapy or surgery, or patients with pulmonary or nonpulmonary distant metastases on presentation to the First Affiliated Hospital, Zhejiang University School of Medicine, were excluded from the present study.

$q P C R$ analysis. Total RNA was extracted from the frozen tumor tissues using TRIzol ${ }^{\circledR}$ Reagent according to the manufacturer's instructions (Invitrogen Life Technologies, Carlsbad, CA, USA). Total RNA was reverse transcribed into single stranded complementary (c)DNA using a moloney-murine leukemia virus (M-MLV) reverse transcriptase (Promega Corporation, Madison, WI, USA). Briefly, RNA was denatured by heating for $5 \mathrm{~min}$ at $70^{\circ} \mathrm{C}$, followed by rapid cooling on ice. The RNA was used for reverse transcription in a $25-\mu 1$ reaction volume containing $2 \mu \mathrm{g}$ total RNA, 25 units RNase inhibitor, $0.5 \mathrm{mmol} / \mathrm{l}$ each deoxyribonucleotide triphosphate, $1.5 \mu \mathrm{mol} / 1$ reverse primer and 200 units M-MLV reverse transcriptase. For reverse transcription, the reactions were incubated at $42^{\circ} \mathrm{C}$ for $60 \mathrm{~min}$. The expression of pIgR was analyzed using a fluorescence-based real-time detection method with the ABI PRISM 7700 Sequence Detection System (PerkinElmer, Inc., Waltham, MA, USA) as described previously $(24,25)$. The specific primer pairs and fluorescent probes for $\mathrm{pIgR}$ and glyceraldehyde-3-phosphate dehydrogenase (GAPDH) are shown in Table I. GAPDH served as an endogenous control. qPCR analysis was performed in triplicate for each sample. The $25-\mu 1 \mathrm{qPCR}$ reaction consisted of $1 \mu \mathrm{l} \mathrm{cDNA}$ template, $1 \mu \mathrm{l}$ each of sense and anti-sense primers, $0.75 \mu \mathrm{l}$ 5' FAM- and 3' TAMARA-labeled oligonucleotide probes, $2 \mu \mathrm{l}$ dNTP mixture, $5 \mu \mathrm{l} 5 \mathrm{X}$ reaction buffer and $0.125 \mu \mathrm{l}$ Taq DNA polymerase. The cycling conditions were as follows: $50^{\circ} \mathrm{C}$ for $2 \mathrm{~min}$ and $95^{\circ} \mathrm{C}$ for $10 \mathrm{~min}$, followed by 46 cycles of $95^{\circ} \mathrm{C}$ for $15 \mathrm{sec}$ and $60^{\circ} \mathrm{C}$ for $1 \mathrm{~min}$. To determine the relative expression of pIgR mRNA in the individual tissue samples the $\mathrm{Ct}$ values were normalized using the $\mathrm{Ct}$ value for GAPDH mRNA (25).

Immunohistochemistry. Selected tumor samples were fixed in $10 \%$ neutral-buffered formalin and embedded in paraffin. Sections (size, $5 \mu \mathrm{M}$ ) were cut, dewaxed, rehydrated and subjected to antigen retrieval. Subsequent to blocking endogenous peroxidase activity, the sections were incubated with the primary antibodies against pIgR (1:100; Epitomics Inc., Burlingame, CA, USA) overnight at $4^{\circ} \mathrm{C}$. Immunohistochemistry was performed using the streptavidin-biotin-peroxidase complex method (Lab Vision Corporation, Fremont, CA, USA). The slides were analyzed and images were captured using an Olympus BX60 microscope (Olympus Corporation, Tokyo, Japan). Sections that are known to stain positively were incubated in each batch and negative controls were also established by replacing the primary antibody with pre-immune serum.

Expression analysis of pIgR in the tumor tissue was performed by comparing the staining intensity with the percentage of immunoreactive cells. Staining intensity was arbitrarily scored on a scale of four grades: 0, No staining; 1 , weak staining; 2 , moderate staining; and 3 , strong staining. The percentage of positive cells was scored according to the following grades: $0,0 \% ; 1,1-25 \% ; 2,26-50 \%$; and $3,>50 \%$. pIgR staining positivity was determined using the following formula: Overall score $=$ positive percentage score $\mathrm{x}$ staining 


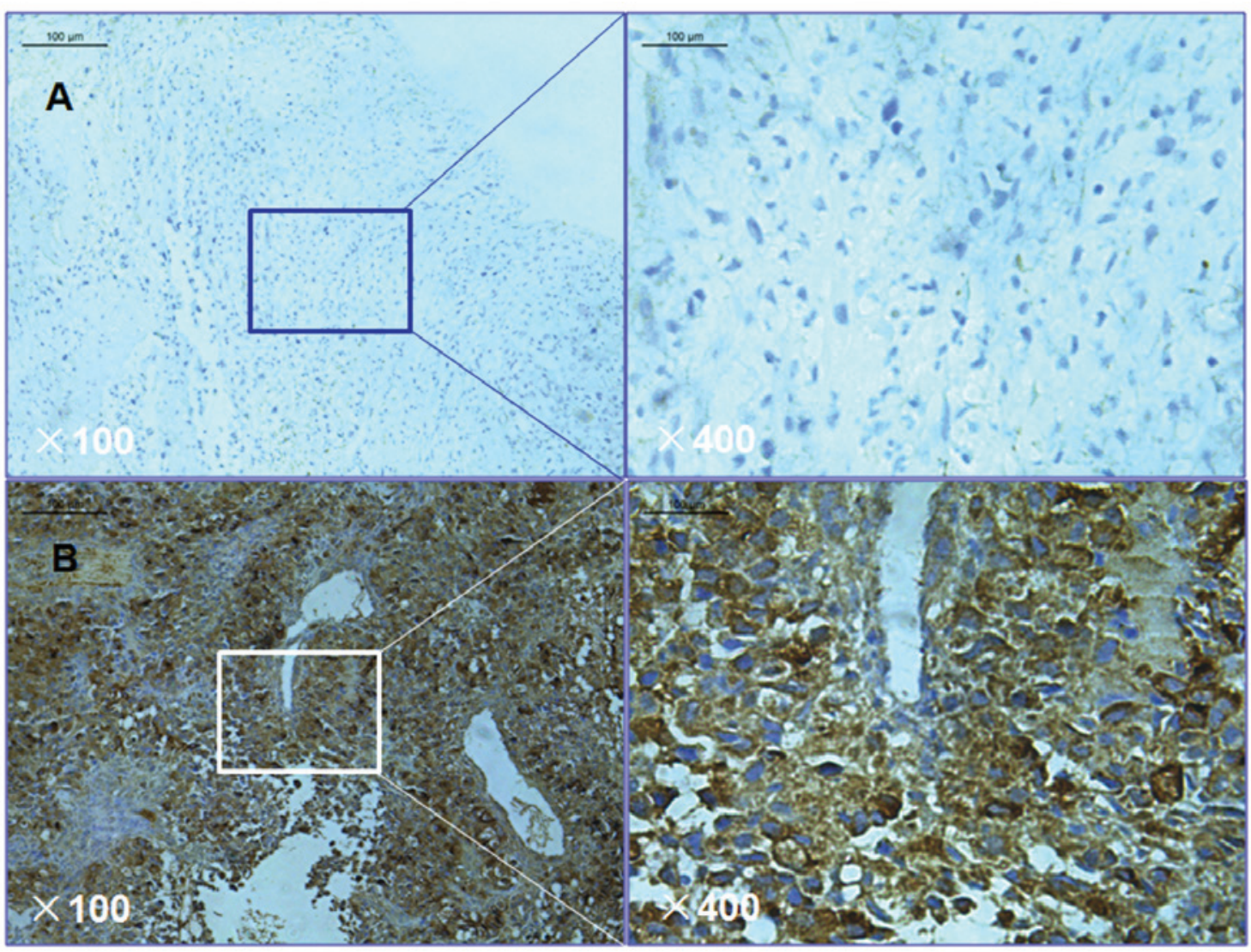

Figure 1. Polymeric immunoglobulin receptor (pIgR) expression in osteosarcoma tissues visualized via immunohistochemical staining. (A) Negative and (B) positive expression of pIgR. (A\&B) Left panel; magnification, x100: Right panel, magnification, x400.

intensity score. A score of 0 was termed 0 , a score $>0$ and $\leq 2$ was termed 1 , a score $>2$ and $\leq 6$ was termed 2 and a score $>6$ and $\leq 9$ was termed 3 . Tumor samples graded as level 0 or 1 were defined as negative for $\mathrm{pIgR}$ expression, whereas samples graded as level 2 or 3 were defined as positive for pIgR expression.

Follow-up. Patient follow-up consisted of physical examination, including CT, MRI and X-ray scans every three months for the first five years, then annually thereafter. Patients were followed up until mortality or until the date of the final follow-up. Follow-up was terminated on December 31, 2012. The median follow-up was 41.7 months (range, 10-179 months).

Statistical analysis. All statistical analyses were performed using SPSS 16.0 software (SPSS, Inc., Chicago, IL, USA). Data are expressed as the mean \pm standard error of the mean. Clinicopathological parameters were analyzed via two-tailed $\chi^{2}$ and two-tailed t-tests to assess the association between pIgR expression and clinicopathological parameters. Overall survival (OS) curves for patients with positive and negative pIgR expression were estimated using the Kaplan-Meier method. Survival functions were compared using the log-rank test. Univariate and multivariate analyses were based on the Cox proportional-hazards regression model. Factors that significantly influenced OS were used in the Cox proportional-hazards regression model for multivariate analysis. $\mathrm{P}<0.05$ was considered to indicate a statistically significant difference.

\section{Results}

pIgR expression in osteosarcoma. qPCR analysis was performed to assess $p I g R$ gene expression in 22 fresh frozen osteosarcoma samples. The housekeeping gene, GAPDH served as a control. pIgR expression was found to be positive in $15 / 22(68.2 \%)$ patients with osteosarcoma (Table II).

To determine the frequency of positive expression of the $p I g R$ gene in osteosarcoma, $\mathrm{pIgR}$ expression was analyzed in 136 paraffin-embedded osteosarcoma tissue samples using immunohistochemical staining. Among the 136 osteosarcoma samples, $p \operatorname{Ig} R$ was observed to be expressed in 93/136 (68.4\%) samples (Fig. 1). This finding indicates that pIgR may be key in osteosarcoma. Table III demonstrates the association between pIgR expression and clinicopathological characteristics of the 136 osteosarcoma tissue samples, including age, gender, tumor location, histological type and grade.

pIgR expression is associated with poor survival in patients with osteosarcoma. The OS curves for patients with osteosarcoma, subdivided on the basis of pIgR expression, are shown in Fig. 2. Positive pIgR expression was found to be associated with poor prognosis in patients with osteosarcoma (log-rank test, $\mathrm{P}<0.001)$. Univariate analysis revealed that patients who exhibited a positive expression for $\mathrm{pIgR}$ had a significantly poorer prognosis compared with those who exhibited a negative expression for $\mathrm{pIgR}(\mathrm{P}<0.001$; Table IV). Multivariate analysis demonstrated that positive pIgR expression was an independent and significant predictor in OS (Table V). 
Table II. pIgR mRNA expression in osteosarcoma samples.

\begin{tabular}{|c|c|c|}
\hline \multirow[b]{2}{*}{ Tumor tissue } & \multicolumn{2}{|c|}{ pIgR mRNA expression } \\
\hline & $\begin{array}{c}\text { Samples } \\
\text { (positive/total) }\end{array}$ & $\begin{array}{l}\text { Level of expression } \\
\quad(\text { mean } \pm \text { SEM })\end{array}$ \\
\hline Osteosarcoma & $15 / 22$ & $0.32 \pm 0.07$ \\
\hline \multicolumn{3}{|c|}{$\begin{array}{l}\text { mRNA expression was assessed using quantitative polymerase chain } \\
\text { reaction analysis and was expressed relative to GAPDH mRNA } \\
\text { expression. The criterion for detectable expression for each transcript } \\
\text { was an mRNA level } \geq 0.02 \% \text { of GAPDH mRNA. pIgR, polymeric } \\
\text { immunoglobulin receptor; SEM, standard error of the mean. }\end{array}$} \\
\hline
\end{tabular}

Table III. Association between pIgR expression and clinicopathological parameters in 136 patients with osteosarcoma.

\begin{tabular}{|c|c|c|c|}
\hline \multirow[b]{2}{*}{ Parameter } & \multicolumn{3}{|c|}{ pIgR expression } \\
\hline & Positive & Negative & P-value \\
\hline Patients (n/\%) & $93 / 68.4$ & $43 / 31.6$ & - \\
\hline Age (years; mean \pm SEM) & $22.7 \pm 7.2$ & $24.3 \pm 8.5$ & 0.832 \\
\hline \multicolumn{4}{|l|}{ Gender } \\
\hline Female (n/\%) & $43 / 46.2$ & $21 / 48.8$ & 0.637 \\
\hline Male (n/\%) & $50 / 53.8$ & $22 / 51.2$ & - \\
\hline \multicolumn{4}{|l|}{ Tumor location } \\
\hline Femur & $45 / 48.4$ & $22 / 51.2$ & 0.635 \\
\hline Tibia & $23 / 24.7$ & $11 / 25.6$ & - \\
\hline Humerus & $8 / 8.6$ & $3 / 7.0$ & - \\
\hline Fibula & $6 / 6.5$ & $2 / 4.7$ & - \\
\hline Pelvis & $5 / 5.4$ & $2 / 4.7$ & - \\
\hline Other & $6 / 6.5$ & $3 / 7.0$ & - \\
\hline \multicolumn{4}{|l|}{ Histological type } \\
\hline Osteoblastic & $47 / 50.5$ & $23 / 53.5$ & 0.712 \\
\hline Chondroblastic & $22 / 23.7$ & $11 / 25.6$ & - \\
\hline Fibroblastic & $18 / 19.4$ & $7 / 16.3$ & - \\
\hline Telangetatic & $6 / 6.5$ & $2 / 4.7$ & - \\
\hline \multicolumn{4}{|l|}{ Histological grade } \\
\hline Low & $22 / 23.7$ & $9 / 20.9$ & 0.563 \\
\hline High & $71 / 76.3$ & $34 / 79.1$ & - \\
\hline
\end{tabular}

pIgR, polymeric immunoglobulin receptor; SEM, standard error of the mean.

\section{Discussion}

Osteosarcoma is the most common type of malignant primary bone tumor (1). Osteosarcoma has a high metastatic potential, most commonly spreading to the lungs and bone (26). The relatively high mortality rate associated with osteosarcoma is predominantly associated with systemic metastasis, particularly pulmonary metastasis (27). The five-year survival rate for patients with osteosarcoma metastases is $20 \%$ compared with $65 \%$ for patients with localized disease and the majority
Table IV. Univariate analysis of OS in patients with osteosarcoma following surgical resection.

\begin{tabular}{lcc}
\hline & \multicolumn{2}{c}{ OS } \\
\cline { 2 - 3 } pIgR expression & Patients (n) & P-value \\
\hline Positive & 93 & $<0.001$ \\
Negative & 43 & - \\
Total & 136 & - \\
\hline
\end{tabular}

pIgR, polymeric immunoglobulin receptor; OS, overall survival. $\mathrm{P}<0.001$, compared with the patients with negative $\mathrm{pIgR}$ expression.

Table V. Multivariate analysis of overall survival in patients with osteosarcoma following surgical resection.

\begin{tabular}{lcc}
\hline Parameter & HR $(95 \% \mathrm{CI})$ & P-value \\
\hline Positive pIgR expression & $2.582(1.763-3.585)$ & $<0.001$ \\
\hline $\begin{array}{l}\text { HR, hazard ratio. CI, confidence interval; pIgR, polymeric immuno- } \\
\text { globulin receptor. }\end{array}$ & \\
\hline
\end{tabular}

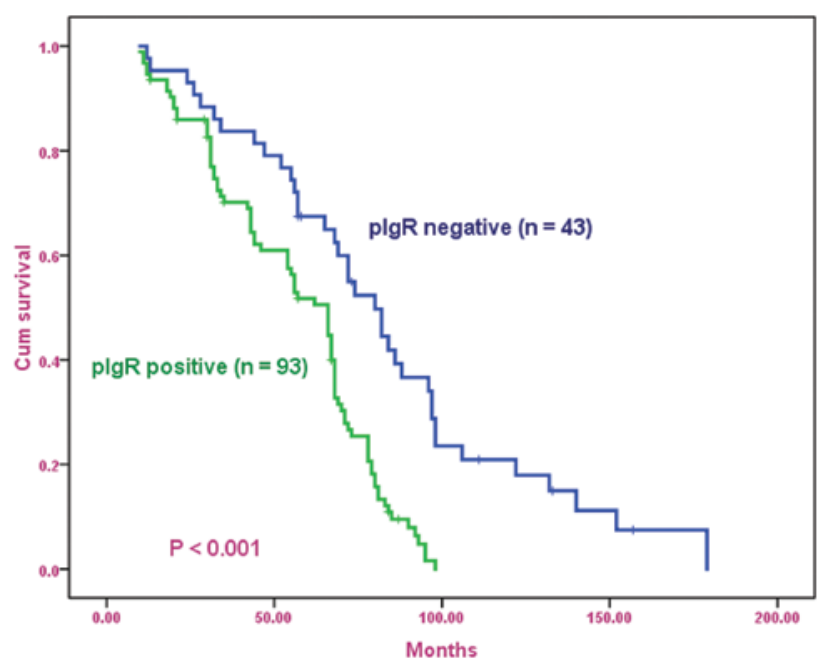

Figure 2. Kaplan-Meier survival curves of patients with osteosarcoma undergoing surgical resection, grouped by $\mathrm{pIgR}$ expression in tumor tissues. The survival rate of the patients with osteosarcoma in the pIgR-negative expression group $(n=43)$ was significantly higher than that of the patients in the pIgR-positive expression group $(n=93)$. $\mathrm{P}<0.001$. $\mathrm{pIgR}$, polymeric immunoglobulin receptor; Cum, cumulative.

of the mortalities associated with osteosarcoma are the result of metastasis $(5,28)$. Despite aggressive treatment modalities, including high-dose chemotherapy and wide tumor resection, the five-year survival rate for patients with osteosarcoma is between 55 and $60 \%$ and $<40 \%$ for patients with pulmonary metastases $(4,5)$. Thus, the identification of biomarkers, which offer prognostic insight and guide clinical treatment, is considered to be important.

The present study aimed to investigate the prognostic value of $\mathrm{pIgR}$ in patients with osteosarcoma following surgical 
resection. pIgR is a glycoprotein present on glandular epithelial cells that functions as a receptor for pIg. pIgR transports pIgA into external secretions as secretory $\operatorname{IgA}$, which is critical for mucosal tissue defense (29). pIgR has been reported to be overexpressed in colon (11) and breast cancer $(12,13)$, endometrial carcinoma $(14,15)$, bladder carcinoma (16), and HCC $(17,18)$; however, the clinical significance of pIgR remains unknown. The prognostic value of $\mathrm{pIgR}$ in patients with malignancy also remains unclear. Ai et al (18) were the first to report the clinical significance of pIgR in HCC. pIgR was identified as a prognostic biomarker for HCC and was shown to have a role in the hepatitis B infection, chronic liver inflammation, the induction of the epithelial-mesenchymal transition, HCC recurrence and metastatic progression (18). The role of $\mathrm{pIgR}$ in osteosarcoma required investigation, thus the present study aimed to immunohistochemically assess pIgR expression in 136 pretherapeutic tumor samples and correlate the expression with clinicopathological parameters in order to identify the potential prognostic implications of pIgR in osteosarcoma.

In the present study, pIgR expression was analyzed in cryopreserved osteosarcoma tissues from 22 patients using qPCR analysis and was found to be expressed in $15(68.2 \%)$ patients. pIgR expression was subsequently assessed in paraffin-embedded osteosarcoma tissue samples from 136 osteosarcoma patients with clinical follow-up records; positive pIgR expression was identified in 93 (68.4\%) of the paraffin-embedded osteosarcoma tissue samples. Univariate analysis revealed that $\mathrm{OS}$ for patients with a positive $\mathrm{pIgR}$ expression in osteosarcoma tissues was significantly poorer compared with patients with negative pIgR expression. Furthermore, multivariate analysis showed that positive pIgR expression in osteosarcoma tissues was an independent prognostic factor for OS following surgical resection $(\mathrm{P}<0.001)$. To the best of our knowledge, this is the first study to indicate that $\mathrm{pIgR}$ has a role in osteosarcoma, however, this requires further investigation.

In conclusion, to the best of our knowledge, this is the first study to show that positive expression of $\mathrm{pIgR}$ is significantly associated with a poor prognosis in osteosarcoma patients. Therefore, pIgR may be a novel predictor for poor prognosis in osteosarcoma patients following surgical resection and may be a promising candidate for targeted osteosarcoma therapy.

\section{References}

1. Ma O, Cai WW, Zender L, Dayaram T, Shen J, Herron AJ, Lowe SW, Man TK, Lau CC and Donehower LA: MMP13, Birc2 (cIAP1), and Birc3 (cIAP2), amplified on chromosome 9, collaborate with p53 deficiency in mouse osteosarcoma progression. Cancer Res 69: 2559-2567, 2009.

2. Janeway KA and Grier HE: Sequelae of osteosarcoma medical therapy: a review of rare acute toxicities and late effects. Lancet Oncol 11: 670-678, 2010

3. Caudill JS and Arndt CA: Diagnosis and management of bone malignancy in adolescence. Adolesc Med State Art Rev 18 $62-78,2007$

4. Bacci G, Rocca M, Salone M, Balladelli A, Ferrari S, Palmerini E, Forni C and Briccoli A: High grade osteosarcoma of the extremities with lung metastases at presentation: treatment with neoadjuvant chemotherapy and simultaneous resection of primary and metastatic lesions. J Surg Oncol 98: 415-420, 2008.
5. Bielack SS, Kempf-Bielack B, Delling G, Exner GU, Flege S, Helmke K, Kotz R, Salzer-Kuntschik M, Werner M, Winkelmann W, et al: Prognostic factors in high-grade osteosarcoma of the extremities or trunk: an analysis of 1,702 patients treated on neoadjuvant cooperative osteosarcoma study group protocols. J Clin Oncol 20: 776-790, 2002.

6. Errani C, Longhi A, Rossi G, Rimondi E, Biazzo A, Toscano A, Alì N, Ruggieri $\mathrm{P}$, Alberghini M, Picci $\mathrm{P}$, et al: Palliative therapy for osteosarcoma. Expert Rev Anticancer Ther 11: 217-227, 2011.

7. Denning GM: IL-4 and IFN-gamma synergistically increase total polymeric IgA receptor levels in human intestinal epithelial cells. Role of protein tyrosine kinases. J Immunol 156: 4807-4814, 1996.

8. Kvale D, Løvhaug D, Sollid LM and Brandtzaeg P: Tumor necrosis factor-alpha up-regulates expression of secretory component, the epithelial receptor for polymeric Ig. J Immunol 140: 3086-3089, 1988.

9. Rojas R and Apodaca G: Immunoglobulin transport across polarized epithelial cells. Nat Rev Mol Cell Biol 3: 944-955, 2002.

10. Kaetzel CS: The polymeric immunoglobulin receptor: bridging innate and adaptive immune responses at mucosal surfaces. Immunol Rev 206: 83-99, 2005.

11. Poger ME, Hirsch BR and Lamm ME: Synthesis of secretory component by colonic neoplasms. Am J Pathol 82: 327-338, 1976.

12. Harris JP, Caleb MH and South MA: Secretory component in human mammary carcinoma. Cancer Res 35: 1861-1864, 1975.

13. Harris JP and South MA: Secretory component: a glandular epithelial cell marker. Am J Pathol 105: 47-53, 1981.

14. DeSouza LV, Krakovska O, Darfler MM, Krizman DB, Romaschin AD, Colgan TJ and Siu KW: mTRAQ-based quantification of potential endometrial carcinoma biomarkers from archived formalin-fixed paraffin-embedded tissues. Proteomics 10: 3108-3116, 2010.

15. DeSouza LV, Romaschin AD, Colgan TJ and Siu KW: Absolute quantification of potential cancer markers in clinical tissue homogenates using multiple reaction monitoring on a hybrid triple quadrupole/linear ion trap tandem mass spectrometer. Anal Chem 81: 3462-3470, 2009.

16. Rossel M, Billerey C, Bittard H, Ksiazek P, Alber D, Revillard JP and Vuitton DA: Alterations in polymeric immunoglobulin receptor expression and secretory component levels in bladder carcinoma. Urol Res 19: 361-366, 1991.

17. Rossel M, Seilles E, Voigt JJ, Vuitton D, Legait N and Revillard JP: Polymeric Ig receptor expression in hepatocellular carcinoma. Eur J Cancer 28A: 1120-1124, 1992.

18. Ai J, Tang Q, Wu Y, Xu Y, Feng T, Zhou R, Chen Y, Gao X, Zhu Q, Yue X, et al: The role of polymeric immunoglobulin receptor in inflammation-induced tumor metastasis of human hepatocellular carcinoma. J Natl Cancer Inst 103: 1696-1712, 2011.

19. Xiao T, Ying W, Li L, Hu Z, Ma Y, Jiao L, Ma J, Cai Y, Lin D, Guo $\mathrm{S}$, et al: An approach to studying lung cancer-related proteins in human blood. Mol Cell Proteomics 4: 1480-1486, 2005.

20. Rossel M, Brambilla E, Billaud M, Vuitton DA, Blanc-Jouvan F, Biichle S and Revillard JP: Nonspecific increased serum levels of secretory component in lung tumors: relationship to the gene expression of the transmembrane receptor form. Am J Respir Cell Mol Biol 9: 341-346, 1993.

21. Makawita S, Smith C, Batruch I, Zheng Y, Rückert F, Grützmann R, Pilarsky C, Gallinger S and Diamandis EP: Integrated proteomic profiling of cell line conditioned media and pancreatic juice for the identification of pancreatic cancer biomarkers. Mol Cell Proteomics 10: M111.008599, 2011.

22. Kvale D, Norstein J, Meling GI, Børmer OP, Brandtzaeg P, Langmark $F$ and Rognum TO: Circulating secretory component in relation to early diagnosis and treatment of liver metastasis from colorectal carcinomas. J Clin Pathol 45: 568-571, 1992.

23. Enneking WF, Spanier SS and Goodman MA: A system for the surgical staging of musculoskeletal sarcoma. 1980. Clin Orthop Relat Res 415: 4-18, 2003.

24. Bruno ME and Kaetzel CS: Long-term exposure of the HT-29 human intestinal epithelial cell line to TNF causes sustained up-regulation of the polymeric Ig receptor and proinflammatory genes through transcriptional and posttranscriptional mechanisms. J Immunol 174: 7278-7284, 2005. 
25. Khattar NH, Lele SM and Kaetzel CS: Down-regulation of the polymeric immunoglobulin receptor in non-small cell lung carcinoma: correlation with dysregulated expression of the transcription factors USF and AP2. J Biomed Sci 12: 65-77, 2005.

26. Laverdiere C, Hoang BH, Yang R, Sowers R, Qin J, Meyers PA, Huvos AG, Healey JH and Gorlick R: Messenger RNA expression levels of CXCR4 correlate with metastatic behavior and outcome in patients with osteosarcoma. Clin Cancer Res 11: 2561-2567, 2005.
27. Urakawa H, Nishida Y, Nakashima H, Shimoyama Y, Nakamura $S$ and Ishiguro N: Prognostic value of indoleamine 2,3-dioxygenase expression in high grade osteosarcoma. Clin Exp Metastasis 26: 1005-1012, 2009.

28. Eccles SA and Welch DR: Metastasis: recent discoveries and novel treatment strategies. Lancet 369: 1742-1757, 2007.

29. Mestecky J and McGhee JR: Immunoglobulin A (IgA): molecular and cellular interactions involved in IgA biosynthesis and immune response. Adv Immunol 40: 153-245, 1987. 